\title{
Performance Improvement of Freight Logistics Hub Selection in Thailand by Coordinated Simulation and AHP
}

\author{
Jirapat Wanitwattanakosol ${ }^{\dagger}$ \\ Department of Industrial Engineering, Faculty of Engineering Chiang Mai University, \\ Chiang Mai 50200, THAILAND \\ Tel: +66-53-944-125, E-mail: iejirapat@gmail.com \\ Pongsak Holimchayachotikul \\ College of Arts, Media and Technology, \\ Chiang Mai University, Chiang Mai, 50200, THAILAND \\ Tel: +66-53-920-299, E-mail: g490631075@gmail.com \\ Phatchari Nimsrikul \\ Department of Industrial Engineering, \\ Faculty of Engineering Chiang Mai University, Chiang Mai 50200, THAILAND \\ Tel: +66-53-944-125, E-mail: bowlink20@hotmail.com \\ Apichat Sopadang \\ Department of Industrial Engineering, \\ Faculty of Engineering Chiang Mai University, Chiang Mai 50200, THAILAND \\ Tel: +66-53-944-125, E-mail: apichat@chiangmai.ac.th
}

Received, February 19, 2010; Revised, April 21, 2010; Accepted, May 17, 2010

\begin{abstract}
This paper presents a two-phase quantitative framework to aid the decision making process for effective selection of an efficient freight logistics hub from 8 alternatives in Thailand on the North-South economic corridor. Phase 1 employs both multiple regression and Pearson Feature selection to find the important criteria, as defined by logistics hub score, and to reduce number of criteria by eliminating the less important criteria. The result of Pearson Feature selection indicated that only 5 of 15 criteria affected the logistics hub score. Moreover, Genetic Algorithm (GA) was constructed from original 15 criteria data set to find the relationship between logistics criteria and freight logistics hub score. As a result, the statistical tools are provided the same 5 important criteria, affecting logistics hub score from GA, and data mining tool. Phase 2 performs the fuzzy stochastic AHP analysis with the five important criteria. This approach could help to gain insight into how the imprecision in judgment ratios may affect their alternatives toward the best solution and how the best alternative may be identified with certain confidence. The main objective of the paper is to find the best alternative for selecting freight logistics hub under proper criteria. The experimental results show that by using this approach, Chiang Mai province is the best place with the confidence interval $95 \%$.
\end{abstract}

Keywords: Pearson Feature Selection, Multiple Regression, Genetic Algorithm, Fuzzy AHP, Simulation, Freight Logistics Hub

\section{INTRODUCTION}

Supply chain management (SCM) has risen to prominence over ten years (Cooper et al., 1997). There are many reasons for the popularity of the concept. Specific drivers may be traced to trends in global sourcing, an emphasis on time and quality-based competition, and their respective contributions to greater environmental

$\dagger$ : Corresponding Author 
uncertainty (Mentzer et al., 2001). New and Payne (1995) describe supply chain management as the chain linking each element of the manufacturing and supply process from raw materials through to the end user, encompassing several organizational boundaries. The short-term objective of SCM is primarily to increase productivity and reduce inventory and cycle time, while the longterm strategic goal is to increase customer satisfaction, market share and profits for all members of the virtual organization (Tan, 2001).

One of various supply chain strategies is to select facility location. The ability of a firm to produce and market its products effectively or to deliver high-quality services is dependent in part on the location of the firm's facilities (Jayaraman, 1998). However, the strategy of selection usually involves subjective and qualitative judgment. In this sense, the procedure of location selection is required to handle several complex factors in a better sensible and logical manner. Thus, the strategy selection is a kind of multiple criteria decision making (MCDM) problem and required MCDM methods to solve it appropriately.

The MCDM procedure can be employed to determine a compromise solution for a problem with conflicting criteria. The MCDM has various methods to solve the problem such as Analytic Hierarchy Process (AHP) (Saaty, 1980), VlseKriterijumska Optimizacija I Kompromisno Resenje in Serbian (VIKOR) (Opricovic, 1998), Analytical Network Process (ANP) (Saaty, 1996), Decision Making Trial and Evaluation Laboratory (DEMA TEL) (Gabus and Fontela, 1972). Anyway, in some problems have a characteristic is called fuzzy, which plays an important role in human thinking, particularly in the domains of pattern recognition, communication of information and abstraction (Zadeh, 1965). To deal with the various type of information, the concept of data mining always uses to retrieve knowledge in decision support system.

Data mining has been extensively used and received attention from the production field during the 1990s (Han et al., 2001; Irani et al., 1993; Lee, 1993). Presently, Data mining is used not only in business but also in many different areas in supply chain and logistics management including sub-process operation in supply chain and other decision support systems. The data mining techniques can generally be categorized as four types, i.e., association rules, clustering, classification, and prediction (Fayyad et al., 1996; Fu, 1997; PiatetskyShapiro, 1999).

As the MCDM and the data mining have these advantages. Moreover, the research of data mining in supply chain management still has many gap and less considered area to improve (Harding et al., 2006). This paper proposes an effective solution on a combination of fuzzy stochastic AHP and data mining techniques approach to select a suitable freight logistics hub. Also, an empirical study is presented to explain the application of this study. The rest of this paper is organized as follows. In section 2 illustrates the fundamental of this research and reviews related literatures. In section 3 a research framework and methods are described. In section 4, an empirical study in Selection the Freight Logistics Hub in Thailand database is illustrated. Results and discussion of the proposed framework are mentioned and analyzed in section 5. Finally, conclusions and further research directions are provided in section 6 .

\section{LITERETURE RIVEW}

In this section, some essentials of the fuzzy AHP, a stochastic approach for AHP and the methods of data mining are briefly described as follows.

\subsection{Fuzzy Analytic Hierarchy Process}

AHP is a multiple criteria decision-making tool, which was founded by Saaty. This is an eigen value approach to make subjective comparisons for each pair of attributes or alternatives using a ratio scale. It also provides a methodology to calibrate the numeric scale for the measurement of quantitative as well as qualitative performances (Vaidya and Kumar, 2006).

However, many researchers indicate that there are pitfalls associated with the AHP approach. In order to overcome the shortcomings, the fuzzy logic principle was introduced into the AHP for MCDM (Cheng and Mon, 1994).This makes it possible to adopt the AHP in an environment where the input information or the relations between criteria and alternatives are uncertain or imprecise. This paper refines the version used by Lee et al. (1990) and the working procedure can be described as below.

Step 1: Construct a hierarchical structure for the problem be solved. First, define the problem clearly with specifications on its multi-criteria aspects. Next, determine the overall goal, identifying the evaluation criteria. Then, identify the candidate alternatives. Finally, construct the hierarchy.

Step 2: Establish the fuzzy judgment matrix $A$ and weight vector $W$. The fuzzy judgment matrix $A$ is built with all the fuzzy judgment vectors. The weight vector $W$ is used to represent the decision maker's opinion of the relative importance of each criterion during the decision process. All elements in the judgment matrix and weight vectors are represented by triangular fuzzy numbers. In general, for triangular fuzzy number $\tilde{x} .(l, m$, $n)$, the membership function $\mu(x)$ as follows (Figure 1).

$$
\mu(x)=\left\{\begin{array}{cc}
1 & x=m \\
\frac{x-l}{m-l} & l \leq x \leq m \\
\frac{n-x}{n-m} & m \leq x \leq n \\
0 & \text { otherwise }
\end{array}\right.
$$




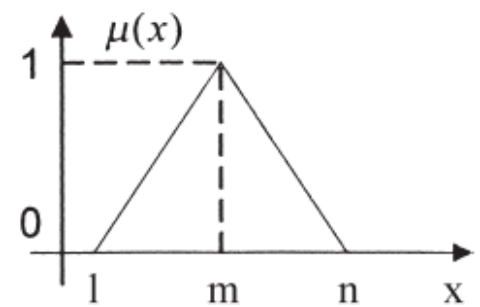

Figure 1. Membership function for triangular fuzzy numbers.

Step 3: Rank all alternatives and select the optimal one. The result of calculating the fuzzy AHP is that the final scores of alternatives are represented in terms of fuzzy numbers. The fuzzy numbers ultimately need to be interpreted for ascertainment which of the alternatives is the best. A defuzzification or ranking process has to be applied, which arranges the fuzzy numbers in order of ranking.

\subsection{Analytic Hierarchy Process: A Stochastic Approach}

In the AHP, the uncertainty is propagated through a hierarchy resulting in the uncertain values for the global AHP weights of decision alternatives. It was clear that, this uncertainty associated with subjective judgmental errors this uncertainty associated with subjective judgmental errors may affect the rank order of decision alternatives and consequently reduce the decision maker's confidence in the obtained results of the AHP (Eskandari and Rabelo, 2007). From the study, the variance of the error parameter $\sigma^{2}$ can directly be estimated from the comparison matrix. A good estimate of the variance of error $\sigma^{2}$ is given by

$$
\sigma^{2}=\frac{2}{(n-1)(n-2)} \sum_{i=1}^{n-1} \sum_{j=i+1}^{n} y_{i j}^{2}
$$

where $\mathrm{n}$ is the size of the matrix, $a_{\mathrm{ij}}$ represents the actual judgment ratio, $w_{i j}=w_{i} / w_{j}$ is the consistent judgment ratio formed from the priority vector $\boldsymbol{w}=\left(w_{1}, w_{2}, \cdots\right.$, $\left.w_{n}\right)$ computed from $\boldsymbol{A}=\left[a_{i j}\right]_{m \times n}$ and $y_{i j}=\ln \left(a_{i j} / w_{i j}\right)$.

Using approximate analysis and simulation, it was found that the variances of the local weights resulting from the subjective errors can be reasonably estimated in term of variance of error by

$$
\sigma_{w_{i}}^{2}=\frac{n^{2}-1}{n^{2}}\left[\sum_{i=1}^{n} w_{i}^{2}-w_{i}^{2}\right] \sigma^{2} w_{i}^{2}
$$

Where $\sigma_{w_{i}}^{2}$ presents the variance of the local weight estimates and provides a degree of accuracy for them.

Rabelo et al. (2007) present a preliminary analysis of the potentials of integrating the group analytic hierarchy process (AHP) technique, system dynamics (SD) and discrete-event simulation (DES) in a comprehensive hybrid approach. This integration enables users to utilize their own experiences, preferences and qualitative assessments which increase the level of their confidence in the decisions resulting in the maximization of shareholder value.

\subsection{Input Feature Selection}

Most of data mining problems often encounter hundreds, or even thousands, of variables. As a result, the greater part of time and effort spent in the modelbuilding process include examining which variables to include in the model. Finding an optimal neural network or a suitable decision tree to a set of variables this may involve much more time than is practical. The variable set to be reduced in size using feature selection, creating a more convenient set of attributes for modeling. Adding feature selection up to the system analytical process has several advantages: 1) reduces and narrow the number of the features that is vital in building a analytical model, 2 ) lessens the computational memory and time requirements for building a predictive model because focus can be focused on the subset of predictors that is most indispensable, 3) conducts to more accurate or more economical models, 4) decreases the time for generating scores because the predictive model is based only on a subset of predictors.

\subsubsection{Pearson's Chi-Square}

A test of independence between $\mathrm{X}$ and $\mathrm{Y}$ involves the difference between the observed and expected frequencies. It called Pearson's chi-square. The expected variable frequencies under the null hypothesis of independence are estimated by $\hat{N}_{i j}=N_{i} . N_{. j} / N$. Pearson's chisquare, underneath the null hypothesis, meets asymptotically to a chi-square distribution with $\chi_{d}^{2}$ degrees of freedom $d=(I-1)(J-1)$. The $p$ value rooted on Pearson's chi-square $\chi^{2} \tilde{x}$. is worked out by $p$ value $=$ $\operatorname{Prob}\left(\chi_{d}^{2}>\chi^{2}\right)$, where $\mu$

$$
\chi^{2}=\sum_{i=1}^{I} \sum_{j=1}^{J}\left(N_{i j}-\hat{N}_{i j}\right)^{2} / \hat{N}_{i j}
$$

where $N_{i j}$ is the number of cases with $\chi=\mathrm{i}$ and $Y=\mathrm{j}$. Independents are ranked by the following rules: 1) sort the predictors out by $p$ value in the rising order, 2) if ties occur, arrange by chi-square in descending order, 3 ) if binds still occur, class by degree of freedom $d$ in soaring order, 4) if ties still occur, arrange by the data file order.

\subsubsection{Multiple Regression}

Multiple regression, a time-honored technique going back to Pearson's 1908 use of it, is employed to answer for (independents) the variance in an interval dependent, based on linear combinations of interval or dummy independent variables. Multiple regression can build that a set of independent variables give a ratio of 
the variance in a dependent variable at a significant level (through a significance test of $R^{2}$ ), and can setup the relative predictive importance of the independent variables (by comparing beta weights). Power terms can be added as independent variables to discover curvilinear effects. Cross-product terms can be adjoined as independent variables to explore interaction effects. The multiple regression equation takes the form

$$
Y=b_{1} x_{1}+b_{2} x_{2}+b_{3} x_{3}+b_{4} x_{4}+\cdots+b_{n} x_{n}+c
$$

\subsubsection{Genetic Algorithm}

Genetic Algorithm (GA) is stochastic search techniques that can search large and complicated spaces on the ideas from natural genetics and evolutionary principle. They have been demonstrated to be effective and robust in searching very large spaces in a wide range of applications. GA performs the search process in four stages: initialization, selection, crossover, and mutation. In the initialization stage, a population of genetic structures (known as chromosomes) that are randomly distributed in the solution space, is selected as the starting point of the search. Chromosomes with a good performance may be chosen for replication several times where as poorly performing structures may not be chosen at all. Such a selective process causes the best-performing chromosomes in the population to occupy an increasingly larger proportion of the population over time. Crossover causes to form a new offspring between two randomly selected "good parents". Crossover operates by swapping corresponding segments of a string representation of the parents and extends the search for a new solution in a far-reaching direction. Mutation is a GA mechanism where a member of the population is randomly chosen and a randomly chosen bit is changed in its bit string representation.

\section{METHODOLOGY}

A schematic diagram of the proposed procedure is shown in Figure 2. This comprises of the combination of Multiple Criteria Decision Making based on fuzzy stochastic AHP and feature selection based on statistics and data mining apply to improve the perform feature selection based on GA, multiple regression and Pearson's chi-square were applied for indicating the significant logistics criteria freight. Data mining use for select the significant criteria from historical data.

In general, most multicriteria methods require definition of quantitative weights for the criteria, in order to evaluate the relative importance of the different criteria. In some problems, it is so difficult to find the proper solution from huge data. To reduction in data gathering costs as well as storage and maintenance costs associated with features that are not necessarily useful for the decision problem of interest. The process of finding pat- terns and relations in large databases is data mining. Data mining using statistical methods as well as machine learning methods such as induced decision trees, neural networks, among others, have been used for this purpose with good results.

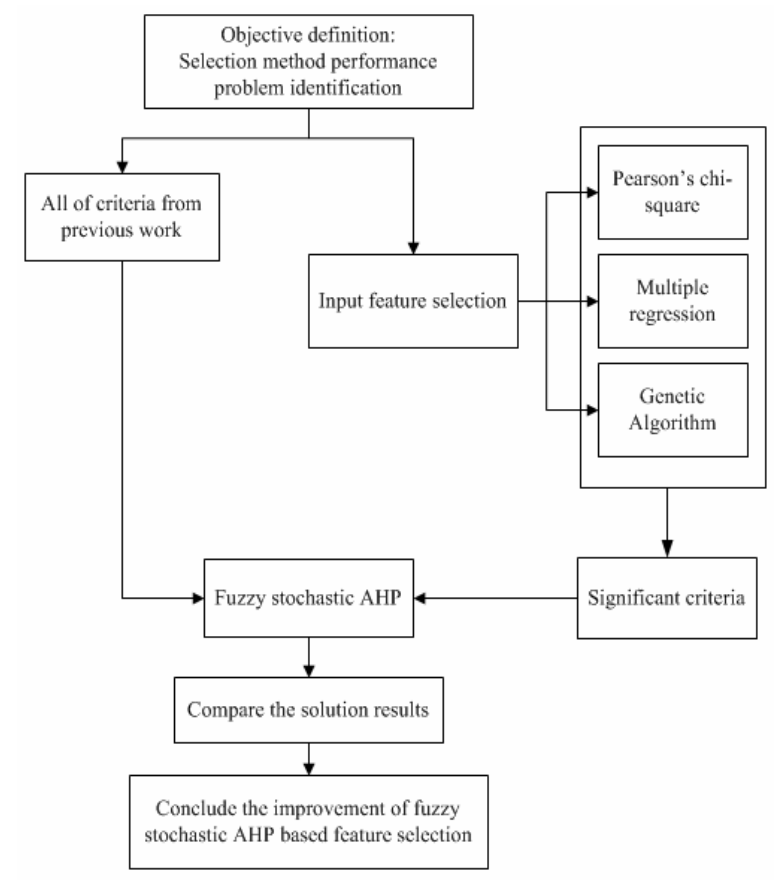

Figure 2. A schematic diagram of the proposed procedure.

Feature selection methods can be used to cull out such problematic features before the data enters the pattern extraction stage in data mining systems. The use of appropriate input data can result in improvements in performance, with minor effort. Selecting the appropriate set of features is extremely important since the feature set selected is the only source of information for any learning algorithm using the data of interest. We evaluate several feature selection methods in this study, as to their effectiveness on preprocessing input criteria for fuzzy stochastic AHP.

A chi-square test is a statistical hypothesis test in which the test statistic has a chi-square distribution is true. In general, the Pearson's chi-square $(x 2)$ test is one of the most common used for chi-square tests whose results are evaluated by reference to the chi-square distribution. This technique uses widely in the test statistics and data mining. Regression analysis can imply a broader range of techniques that ordinarily appreciated. Data mining within a regression framework will rely on regression analysis, broadly defined, so that there is no necessary commitment a priori to any particular function of the predictors. The relationships between the response and the predictors can be determined empirically from the data. Genetic Algorithm (GA) is a class of algorithms that mimic nature's evolution strategy to evo- 
lve a population of chromosomes as potential solutions to optimize problems such as feature selection. The approach starts with a random population of input features. Input features establish what inputs are disregarded during performance test. At each following iteration (called generation), it uses a process similar to natural selection to select superior features and utilize them to breed a new population. At the ultimate pace the best feature is selected. The method is very time-consuming but effective for indicating reciprocally-required inputs and detecting interdependencies.

Next the fuzzy stochastic AHP perform with the significant logistics criteria. Briefly stated, stochastic AHP methodology calculates the global weight variances accounting for judgmental errors resulting from inconsistent pairwise comparisons. Utilizing the global AHP weights and their corresponding estimated variances, Monte Carlo simulation is employed for handling the related uncertainty in the global AHP weights to allow the investigation of whether the differences among the decision alternatives are statistically significant. This type of analysis provides more information for the decision makers in order to make more precise discriminations among competing alternatives. Finally, the result of this proposed approach was compared with the result from the previous fuzzy stochastic AHP.

\section{EMPIRICAL STUDY}

In this section, an empirical study is presented to apply with the proposed method for selecting a favorable freight logistics hub.

\subsection{Problem Description}

Supply chains have become major elements in the global economy. One of the most important strategies is to select an efficient freight logistics hub. Thailand is a developing country; with goals to reform the structure of logistics to create more value, and, innovation while integrating national research and development. Selection of a freight logistics hub in Thailand on North-South economic corridor, indicated in Figure 3, is a key factor to being competitive in manufacturing and service systems.

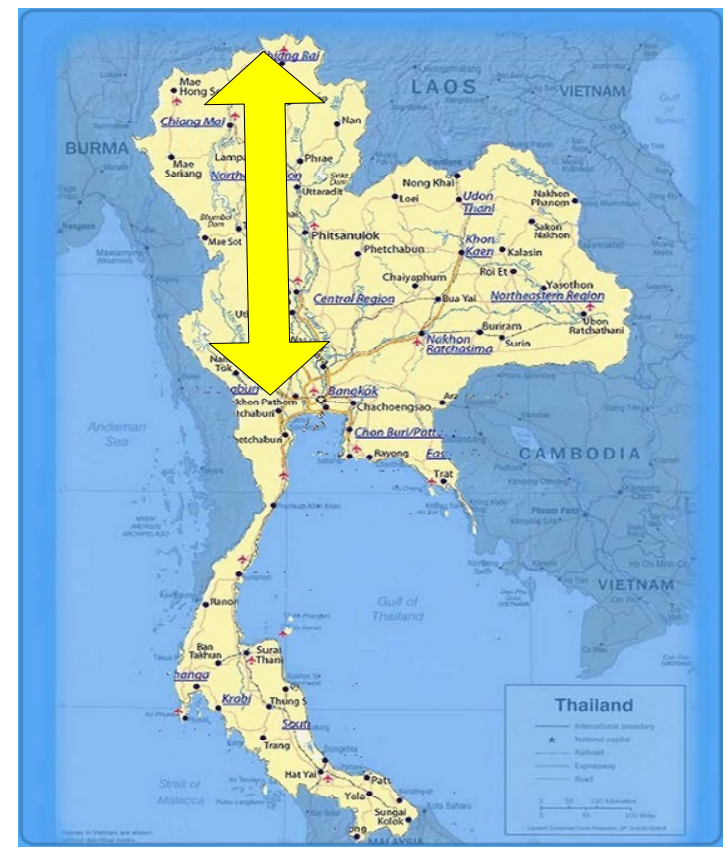

Figure 3. The North-South economics corridors.

As shown in Figure 4, the desired criteria are comprised of location, trade volume, infrastructure, government, and Logistics Service Provider (LSP). Previous studies found that Chiang Mai is the best alternative to perform an efficient freight logistics hub as exhibited in Table 1 (Nimsrikul and Sopadang, 2008; Wanitwattanakosol et al., 2009). Chiang Mai is located in the north of the country and far, about 700 kilometers from Bangkok. Neighboring provinces are (from northeast clockwise) Chiang Rai, Lampang, Lamphun, Tak, and Mae Hong Son. In the north it borders Shan State of Burma.

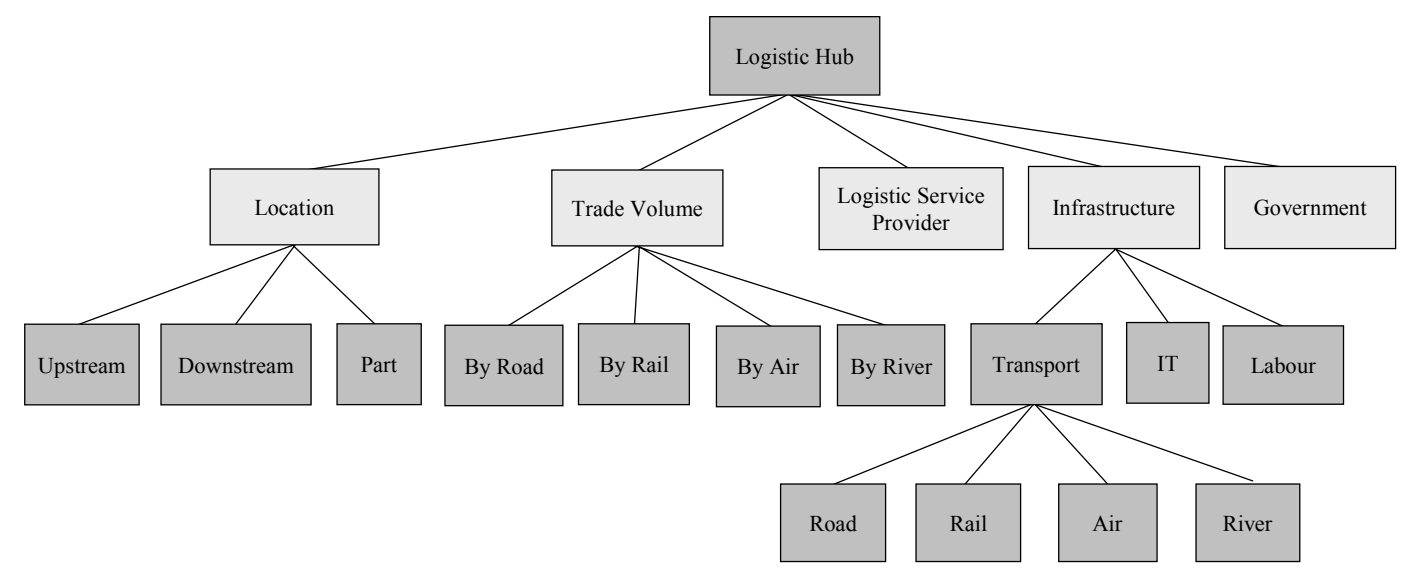

Figure 4. The hierarchy structure of the freight logistic hub problem. 
Table 1. Rank of decision in previous studies.

\begin{tabular}{|l|c|c|}
\hline Alternative & Weight & Rank \\
\hline \hline Chaing Rai & 0.106 & 6 \\
\hline Chiang Mai & 0.241 & 1 \\
\hline Lamphun & 0.128 & 3 \\
\hline Lampang & 0.120 & 4 \\
\hline Phitsanulok & 0.076 & 7 \\
\hline Tak & 0.042 & 8 \\
\hline Nakornsawan & 0.113 & 5 \\
\hline Ayuthaya & 0.188 & 2 \\
\hline
\end{tabular}

In the research process of the previous studies, fuzzy AHP questionnaire collection from the case study companies have consumed much more time on the ground that some of the managers, who replied the questions in questionnaire. Often, the managers did not know the exact meaning of question or have full information for deciding the most suitable answer. Moreover, they had to turn back for historical data consideration. For example, railway trade volume of companies did not update, making it difficult for managers to complete the questionnaire in time. Of many problems with fuzzy AHP questionnaire collection to correct, this research proposes the reduction of unnecessary attributes based on data mining and statistics. Furthermore, a numerical example of the proposed method was demonstrated based on the previous work data.

\subsection{Application of proposed method}

The methodology is as follows. First, data preparation and cleaning of the previous fuzzy AHP questionnaire from eight alternatives is performed to rearrange input and output factor, following feature selection's input and output format. Second, feature selection based on Genetic Algorithm (GA), multiple regression and Pearson's chi-square is applied to indicate the significant logistical criteria of the freight. Logistics hub score was used as output of the feature selection, while fifteen of logistical criteria were used as inputs. Next, the fuzzy stochastic AHP is performed with the significant logistical criteria. Finally, the result of this proposed approach was compared with the result from the previous fuzzy stochastic AHP based on fifteen criteria.

\section{RESULT AND DISCUSSION}

Before feature selection process, data format preparation from the previous work was operated. Logistics hub score was used as output of feature selection, while fifteen of logistics criteria were used as inputs. First, the analysis of Pearson's chi-square was used to build statistical feature selection model at 95\% confidence interval. Five significant predictor inputs had the p-value equal or greater than 0.95 . These were trade volume by road, location part, location upstream, logistics service provider (LSP) and infrastructure in term of labour as shown in Figure 5. Secondly, multiple regression using the enter method was conducted to establish the relationship between logistics criteria and logistics hub score following the relationship equation as

$$
\begin{aligned}
\text { Logistics hub score } & =\text { down } \times 8.056+\text { TV_Road } \times 1.403 \\
& + \text { TV_Rail } \times 0.5869+\operatorname{rail} \times 5.265 \\
& + \text { IT } \times 0.2426+\text { LSP } \times 0.9669 \\
& + \text { Govern } \times 1.603+0.0004576
\end{aligned}
$$

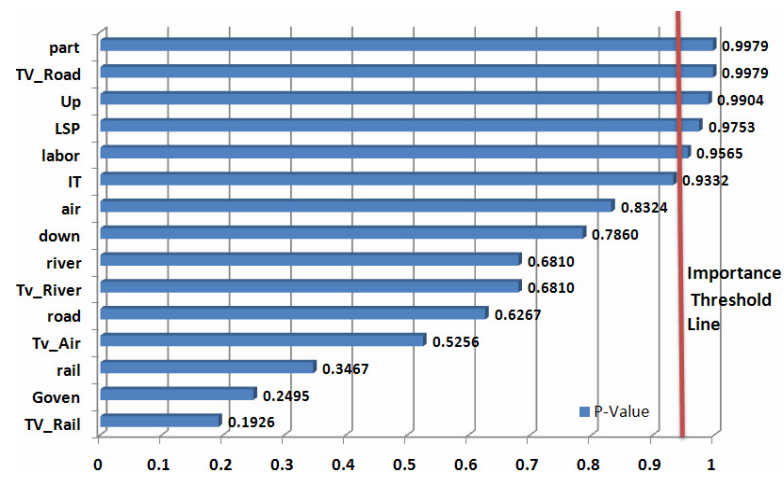

Figure 5. P value based on Pearson's chi-square.

In addition, variable importance from multiple regression method was depicted in Figure 6. Lastly, GA learning process was performed based on the same data of two previous feature selections. Next, the GA component setting for smoothing, unit penalty, sampling, population, generations, crossover and mutation rate were $0.01,0.001,1000,500,500,0.9$ and 0.1 , respectively. Best features chromosome was trade volume by road, trade volume by air, trade volume by river, logistics service provider (LSP) and infrastructure in term of labour. As a result, the statistical tools are provided the same important criteria, effecting on logistics hub score from GA.
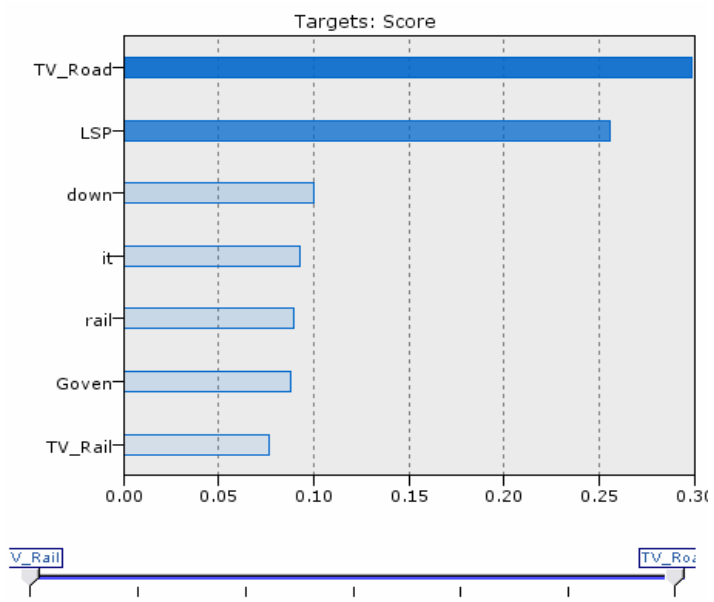

Figure 6. Variable important based on multiple regression. 
Therefore, the fuzzy stochastic AHP analysis was performed with trade volume by road, location part, location upstream, logistics service provider (LSP) and infrastructure in term of labour.

Table 2. The variances of the relative local weights.

\begin{tabular}{|l|l|}
\hline \multicolumn{1}{|c|}{ Main criteria } & $\sigma_{w_{i}}^{2}$ \\
\hline \hline Location & $0.71 \times 10^{-4}$ \\
\hline Trade volume & $1.25 \times 10^{-3}$ \\
\hline Infrastructure & $1.18 \times 10^{-4}$ \\
\hline Logistics service provider & $1.19 \times 10^{-3}$ \\
\hline
\end{tabular}

Table 3. The variances of global weights.

\begin{tabular}{|l|l|}
\hline Province & $\sigma^{2}$ \\
\hline \hline Chiang Rai & $3.0081 \times 10^{-5}$ \\
\hline Chiang Mai & $2.3856 \times 10^{-4}$ \\
\hline Lamphun & $7.3161 \times 10^{-5}$ \\
\hline Lampang & $2.7682 \times 10^{-5}$ \\
\hline Phitsanulok & $4.4126 \times 10^{-6}$ \\
\hline Tak & $3.2101 \times 10^{-6}$ \\
\hline Nakornsawan & $2.6780 \times 10^{-5}$ \\
\hline Ayuthaya & $1.2929 \times 10^{-4}$ \\
\hline
\end{tabular}

Table 4. Some statistics for decision alternatives.

\begin{tabular}{|l|c|c|c|}
\hline \multicolumn{1}{|c|}{ Province } & Mean & S.D. & C.I. (95\%) \\
\hline \hline Chiang Rai & 0.109 & 0.0055 & $(0.0989,0.1204)$ \\
\hline Chiang Mai & 0.298 & 0.0154 & $(0.2678,0.3284)$ \\
\hline Lamphun & 0.115 & 0.0085 & $(0.0987,0.1323)$ \\
\hline Lampang & 0.105 & 0.0053 & $(0.0944,0.1150)$ \\
\hline Phitsanulok & 0.041 & 0.0021 & $(0.0368,0.0451)$ \\
\hline Tak & 0.034 & 0.0018 & $(0.0311,0.0381)$ \\
\hline Nakornsawan & 0.102 & 0.0052 & $(0.0915,0.1118)$ \\
\hline Ayuthaya & 0.208 & 0.0114 & $(0.1855,0.2301)$ \\
\hline
\end{tabular}

To select the best freight logistics hub, we use criteria from Pearson's chi-square. Hence, we can calculate the variances of the relative local weights and consequently the variances of global weights from equation 2 and 3, which are displayed in Table 2 and Table 3, respectively. The overall synthesis of the AHP and some statistics for global weights of decision alternatives based on the recommended methodology are given in Table 4. Figure 7 provides graphical representation of the global weight ranges of alternatives, indicating some degree of judgmental uncertainty. Look at the obtained 95\% confidence interval of global weights gained by the propo- sed methodology; we see that alternative 2, should be selected as the preferred option with the highest global weight point estimate.

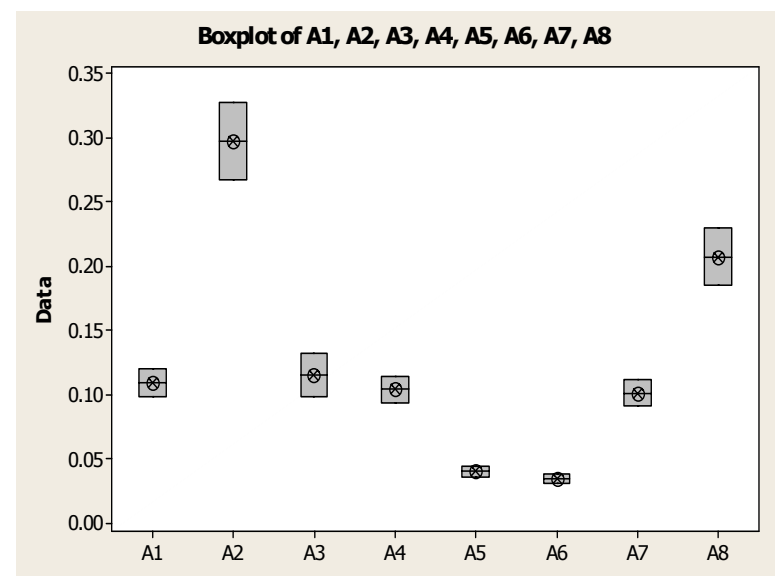

Figure 7. Range of global weights of decision alternatives due to judgmental uncertainty.

Using the simulation approach, the summary of output results of 1,000 replications, Figure 8 presentssample graph from Monte Carlo simulation, is given in Table 5 .We can see that alternative 2 occupied the first place $100 \%$. Alternative 2 does dominate the other alternatives with the confidence level of much more than $95 \%$; thus, the null assumption that alternative 2 is probabilistically optimal (versus the alternate assumption that it is not) is accepted. In this case, the stochastic analysis yields the preference ranking of Chiang Mai is the best solution by considering the degree of judgmental uncertainty found in the input data

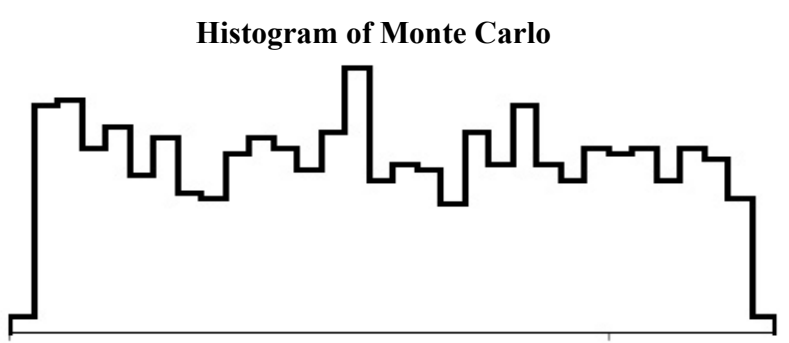

Figure 8. Sample graph from Monte Carlo simulation of Chiang Mai.

The results of fuzzy stochastic AHP based on five significant criteria from feature selection were provided the same alternative solution from previous work. As a comparative approach result, Chiang Mai is the best location for the freight logistics hub in Thailand. Moreover, the research result harmonizes with Chiang Mai's transportation multimodal such as air, rail way and road. Furthermore, Chiang Mai is northern region center of economic system in term of agriculture and electronic industry. 
Table 5. Summary of the simulation results.

\begin{tabular}{|c|c|c|c|c|c|c|c|c|}
\hline \multirow{2}{*}{ Province } & \multicolumn{9}{|c|}{ Rank } \\
\cline { 2 - 9 } & 1 & 2 & 3 & 4 & 5 & 6 & 7 & 8 \\
\hline \hline Chiang Rai & $0.0 \%$ & $0.0 \%$ & $26.5 \%$ & $40.8 \%$ & $23.4 \%$ & $9.3 \%$ & $0.0 \%$ & $0.0 \%$ \\
\hline Chiang Mai & $\mathbf{1 0 0 . 0} \%$ & $0.0 \%$ & $0.0 \%$ & $0.0 \%$ & $0.0 \%$ & $0.0 \%$ & $0.0 \%$ & $0.0 \%$ \\
\hline Lamphun & $0.0 \%$ & $0.0 \%$ & $60.5 \%$ & $20.1 \%$ & $13.1 \%$ & $6.3 \%$ & $0.0 \%$ & $0.0 \%$ \\
\hline Lampang & $0.0 \%$ & $0.0 \%$ & $9.1 \%$ & $24.8 \%$ & $36.2 \%$ & $29.9 \%$ & $0.0 \%$ & $0.0 \%$ \\
\hline Phitsanulok & $0.0 \%$ & $0.0 \%$ & $0.0 \%$ & $0.0 \%$ & $0.0 \%$ & $0.0 \%$ & $98.9 \%$ & $1.1 \%$ \\
\hline Tak & $0.0 \%$ & $0.0 \%$ & $0.0 \%$ & $0.0 \%$ & $0.0 \%$ & $0.0 \%$ & $1.1 \%$ & $98.9 \%$ \\
\hline Nakornsawan & $0.0 \%$ & $0.0 \%$ & $3.9 \%$ & $14.3 \%$ & $27.3 \%$ & $54.5 \%$ & $0.0 \%$ & $0.0 \%$ \\
\hline Ayuthaya & $0.0 \%$ & $100 \%$ & $0.0 \%$ & $0.0 \%$ & $0.0 \%$ & $0.0 \%$ & $0.0 \%$ & $0.0 \%$ \\
\hline Totals & $100 \%$ & $100 \%$ & $100 \%$ & $100 \%$ & $100 \%$ & $100 \%$ & $100 \%$ & $100 \%$ \\
\hline
\end{tabular}

\section{CONCLUSIONS}

This research aims to improve data preparation for logistics management decision making using input feature selection based on statistics and data mining. Moreover, Pearson's chi-square, multiple regression and GA provide the similar significant logistics criteria. We can use this information for fuzzy stochastic AHP recalculation. As a comparison result, we found that input feature selection is enable indirectly reduce the cost and time for questionnaire collection according to effective questionnaire design only the significant criteria.

Further research, input feature selection, based on multivariate input and output relationship analysis with market and economic environmental view, can be added into the first step of multi decision making for site selection to design questionnaire.

\section{ACKNOWLEDGEMENT}

This research was supported financial by the graduate school of Chiang Mai University. Finally, I hope I can contribute and support to improve the IEMS in the future.

\section{REFERENCES}

Cheng, C. H. and Mon, D. L. (1994), Evaluating weapon system by AHP based on fuzzy scale, Fuzzy Sets and Systems, 63, 1-10.

Cooper, M., Ellram, L., Gardner, J., and Hanks, A. (1997), Meshing multiple alliances, Journal of Business Logistics, 18, 67-89.

Eskandari, H. and Rabelo, L. (2007), Handling uncertainty in the analytical hierarchy process: A stochastic approach, International Journal of Informa- tion Technology and Decision Making, 6, 177-189.

Fayyad, U., Piatetsky-Shapiro, G., and Smyth, P. (1996), The KDD process for extracting useful knowledge from volumes of data, Communication of $A C M$, 39(11), 27-34.

Fu, Y. (1997) Data mining, IEEE Potentials, 164, 18-20.

Gabus, A. and Fontela, E. (1972), McA'Nulty, J., and Kjenstad, D. (1996) World problems an invitation to further thought within the framework of DEMATEL, Battelle Geneva Research Centre, Switzerland Geneva.

Han, J. and Kamber, M. (2001), Data mining: concepts and techniques, Morgan Kaufmann Publishers.

Harding, J. A., Shahbaz, M. Srinivas, and Kusiak, A. (2006), Data Mining in Manufacturing: A review, Journal of Manufacturing Science and Engineering, 128, 969-976.

Irani, K. B., Cheng, J., Fayyad, U. M., and Qian, Z. (1993), Applying Machine Learning to Semiconductor Manufacturing, IEEE Expert, 8(1), 41-47.

Jayaraman, V. (1998), Transportation, facility location and inventory issues in distribution network design: An investigation, International Journal of Operations and Production Management, 18(5), 471-494.

Lee, M. H. (1993), Knowledge based factory, Artif. Intell. Eng., 8, 109-125.

Lee, W. B., Lau, H., Liu, Z., and Tam, S. (2001), A fuzzy analytic hierarchy process approach in modular product design, Expert System, 18(1), 32-42.

Mentzer, J. T., De Witt, W., Keebler, J. S., Min, S., Nix, N. W., Smith, C. D., and Zacharia, Z. G. (2001), Defining Supply Chain Management, Journal of Business Logistics, 22, 1-25.

Piatetsky-Shapiro, G. (1999), The data mining industry coming of age, IEEE Intell. Syst., 14(6), 32-34.

Nimsrikul, P. and Sopadang, A. (2008), Application of Multiple Criteria Decision Making for selecting the freight logistics hub in Thailand. Proceedings of 
the GTT Conference, Phetchaburi, Thailand, 930941.

New, S. J. and Payne, P. (1995), Research frameworks in logistics: three models, seven dinners and a survey, International Journal of Physical Distribution and Logistics Management, 25(10), 60-77.

Opricovic, S. (1998), Multicriteria optimization of civil engineering systems, Faculty of Civil Engineering, Belgrade.

Rabelo, L., Eskandari, H., Shaalan, T., and Helal, M. (2007), Value chain analysis using hybrid simulation and AHP, International Journal of Production Economics, 105, 536-547.

Saaty, T. L. (1996), The analytic network process-decision making with dependence and feedback, RWS Publications, Pittsburgh.
Saaty, T. L. (1980), The Analytic Hierarchy Process, McGraw Hill, New York.

Tan, K. C. (2001), A framework of supply chain management literature, European Journal of Purchasing and Supply Management, 7, 39-48.

Vaidya, O. S. and Kumar, S. (2006), Analytic hierarchy process: An overview of applications, European Journal of Operational Research, 169, 1-29.

Wanitwattanakosol, J., Nimsrikul, P., and Sopadang, A. (2009), Selection the freight logistics hub in Thailand on the North-South economic corridors using MCDM: A fuzzy and stochastic approach, Proceedings of the IE Network Conference, Khon Kaen, Thailand, 1366-1371.

Zadeh, L. A. (1965), Fuzzy sets, Information and Control, 8, 338-353. 